\title{
Pengaruh Kualitas Sistem Mobile Banking terhadap Laba Bersih dengan Penggunaan dan Kepuasan Pengguna Sebagai Variabel Intervening
}

\author{
Taufan Adi Kurniawan ${ }^{*}$ Dewi Kusuma Wardani ${ }^{* *}$ Ely Jupita Lestari ${ }^{* * *}$ \\ "Fakultas Ekonomi, Universitas Sarjanawiyata Tamansiswa,taufan.akt@ustjogja.ac.id \\ ${ }^{* *}$ Fakultas Ekonomi, Universitas Sarjanawiyata Tamansiswa, d3wikusuma@gmail.com \\ ${ }^{* * *}$ Fakultas Ekonomi, Universitas Sarjanawiyata Tamansiswa, ellyjupital@gmail.com
}

ARTICLE INFO

Article history:

Received 20 Maret 2019

Received in Revised 15 Agustus 2019

Accepted 20 November 2019

\section{Keywords:}

Delone and Mclean; Mobile

Banking; Net Benefit; System

Quality; User Satisfaction.
A B S T R A C T

The main objective of this research is to analyze the success rate of bri mobile by using the success model of delone and mclean information systems. The type of data used is primary data. The data is taken from distributed questionnaire to BRI bank customers in Yogyakarta using mobile banking services. The sampling method used is convenience sampling. Data were analyzed using Partial Least Squares (PLS) available in SmartPLS 3.0 software application. the results of this study indicate that the quality of the system has a positive effect on usage. System benefits have a direct positive effect on net benefits. Usage is not an intervening variable in the relationship of system quality to net benefits.

Tujuan utama dari penelitian ini adalah untuk menganalisis tingkat keberhasilan mobile bri dengan menggunakan model keberhasilan sistem informasi Delone dan Mclean. Jenis data yang digunakan adalah data primer. Data diambil dari kuesioner yang didistribusikan kepada nasabah bank BRI di Yogyakarta menggunakan layanan mobile banking. Metode pengambilan sampel yang digunakan adalah convenience sampling. Data dianalisis menggunakan Partial Least Squares (PLS) yang tersedia di aplikasi perangkat lunak SmartPLS 3.0. Hasil penelitian ini menunjukkan bahwa kualitas sistem memiliki efek positif pada penggunaan. Kualitas sistem memiliki efek positif secara langsung pada laba bersih. Penggunaan bukan merupakan variabel intervening pada hubungan kualitas sistem terhadap labah bersih. 


\section{PENDAHULUAN}

Saat ini banyak bank swasta maupun bank pemerintah yang memberikan fasilitas mobile banking seperti BCA, BRI, CIMB Niaga, BNI, dan juga Bank Mandiri. Pada kategori E-channel dalam survey TOP Brand, terdapat lima bank konvensional yang berhasil memasuki nominasi TOP Index 2018. Salah satu dari lima bank konvensional itu adalah bank BRI dengan layanan BRI Mobile yang menduduki peringkat tiga selama 3 tahun berturutturut dan kinerja BRI Mobile juga meningkat setiap tahunnya (TOP Brand, 2018). Akan tetapi, permasalahan yang ada saat ini adalah adanya keluhan dari nasabah pengguna BRI Mobile tentang fitur BRI Mobile yang sering mengalami error, gagal login dan sistem respon yang lambat (Detik Info, 2018).

Beberapa faktor yang bisa dijadikan tolak ukur dalam mengukur keberhasilan meningkatnya kinerja BRI Mobile. Faktor-faktor pengukur keberhasilan suatu sistem informasi diantaranya adalah kualitas sistem, kualitas informasi, kualitas layanan, tingkat penggunaan, kepuasan pengguna dan manfaat bersih dari penggunaan sistem informasi. Faktor-faktor tersebut sudah tercakup dalam suatu kerangka model penelitian yang dikhususkan untuk mengukur kesuksesan sistem informasi yaitu model kesuksesan sistem informasi Delone \& Mclean (DeLone, W.H and McLean, 1992).

Penelitian yang dilakukan oleh Motiwalla, Albashrawi, \& Kartal (2018) menemukan bahwa kualitas sistem dapat mempengaruhi tingkat peggunaan dan kepuasan pengguna. Tetapi,disisi lain Rudini (2015) menemukan bahwa kualitas sistem berpengaruh negatif terhadap penggunaan dan kepuausan pengguna. Pada hasil penelitian yang dilakukan oleh Mubarok (2015) ditemukan bahwa penggunaan dan kepuasan pengguna berpengaruh terhadap laba bersih. Sebaliknya, temuan dari penelitian yang dilakukan oleh Muharor, Busaini, \& Fitriah (2015) tidak menemukan adanya pengaruh penggunaan dan kepuasan pengguna terhadap laba bersih.

Perbedaan hasil penelitian ini menjadi bahan yang penting untuk dikaji ulang sehingga dapat diketahui apakah kualitas sistem dapat mempengaruhi laba bersih atas penggunaan layanan BRI Mobile. Penelitian ini juga bertujuan untuk memberikan masukan kepada pihak pengelola BRI Mobile untuk dapat meningkatkan kualitas sistem layanan agar dapat meningkatkan kinerja dan memberikan manfaat yang lebih banyak bagi penggunanya.

Kerangka Pemikiran dan Pengembangan Hipotesis

Berdasarkan teori kesuksesan sistem informasi Delone \& Mclean, kualitas sistem, kualitas informasi, kualitas layanan, penggunaan, kepuasan pengguna, dan manfaat bersih yang dirasakan adalah hal-hal penting yang dapat mempengaruhi keberhasilan suatu sistem informasi (Jogiyanto, 2007). Penelitian yang dilakukan oleh Motiwalla, Albashrawi, \& Kartal (2018) menemukan bahwa kualitas sistem yang baik akan lebih sering digunakan dan dapat memberikan kepuasan tersendiri bagi pemakainya.

Menurut Hafis (2016) semakin tinggi kuantitas pengguna yang menggunakan layanan mobile banking menunujukkan tingkat kepuasan karena semakin sering dan lama pengguna menggunakan layanan mobile banking menjelaskan bahwa pengguna merasa senang dan puas terhadap layanan mobile banking. Penggunaan dan kepuasan pengguna yang tinggi dapat disimpulkan bahwa ada manfaat yang lebih yang didapat oleh pengguna dalam proses penggunaan mobile banking tersebut. Penelitian yang dilakukan oleh Hudin \& Riana (2016) dan Hafis (2016) menemukan bahwa kepuasan pengguna dan penggunaan dapat mempengaruhi laba bersih.

\section{Gambar 1 Kerangka Pemikiran}

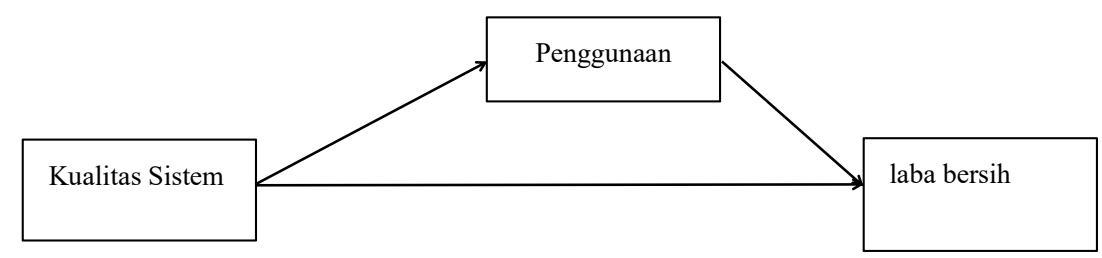


Perumusan HIpotesis:

Hipotesis 1: Kualitas sistem berpengaruh positif terhadap penggunaan mobile banking

Hipotesis 2: Kualitas sistem berpengaruh positif terhadap laba bersih penggunaan mobile banking

Hipotesis 3: Penggunaan berpengaruh positif terhadap laba bersih penggunaan mobile banking

Hipotesis 4: Kualitas sistem berpengaruh terhadap laba bersih melalui penggunaan sebagai variabel intervening

\section{METODE}

\subsection{Pengumpulan Data dan Sampel Penelitian}

Penelitian ini menggunakan data primer. metode pengumpulan data pada penelitian ini dengan cara menyebarkan kuesioner dalam bentuk angket kepada responden untuk diisi guna memperoleh data penelitian. Responden dalam penelitian ini meliputi nasabah pengguna BRI Mobile baik pengguna lama maupun pengguna baru. Teknik pengambilan sampel pada penelitian ini menggunakan metode convenience sampling yaitu teknik pemilihan sampel ketika peneliti tidak memiliki data tentang populasi dalam bentuk sampling frame dan peneliti kemudian memilih sampel berasarkan prinsip kemudahan alam mengambil atau memilih sampel.

\subsection{Variabel Penelitian}

Penelitian ini menggunakan 1 (satu) variabel dependen, 1 (satu) variabel independen, dan 1 (satu) variabel intervening. Variabel dependen yang digunakan dalam penelitian ini adalah laba bersih (net benefits) (Y1). Variabel independen dalam penelitian ini adalah kualitas sistem (system quality) (X1). Variabel intervening dalam penelitian ini adalah penggunaan (use) (Z).

\subsection{Metode Analisis}

Penelitian ini menggunakan metode analisis data dengan menggunakan software SmartPLS versi 3.0 yang dijalankan dengan media komputer. PLS (Partial Least Square) merupakan analisis persamaan struktural (SEM) berbasis varian yang secara simultan dapat melakukan pengujian model pengukuran sekaligus pengujian model struktural. Model pengukuran digunakan untuk uji validitas dan reliabilitas, sedangkan model struktural digunakan untuk uji kausalitas (Abdilllah, 2017).

\section{HASIL DAN PEMBAHASAN}

\subsection{Hasil Uji Model Pengukuran (Outer Model)}

Penyebaran kuesioner dalam penelitian ini dilakukan melalui google form dan angket. Dalam proses pengolahan data, penelitian ini menggunakan 100 kuesioner. Tabulasi data dari kuesioner dilakukan menggunakan Microsoft Excel 2010 dan diolah dengan menggunakan SmartPLS versi 3.0. Sebelumnya telah dilakukan uji pilot test dari 30 kuesioner yang dapat diolah pada penyebaran kuesioner tahap pertama. Pada pengujian validitas yang digunakan untuk pengelolaan data terdapat tiga pernyataan yang tidak valid yaitu KI5, PG2, dan PG5 yang dibuktikan dengan nilai loading factor dibawah 0,50. Sedangkan pernyataan tersebut pada uji pilot test dinyatakan valid. Sehingga pernyataan tersebut harus digugurkan dan diolah kembali. Adapun hasil uji validitas setelah diolah kembali adalah sebagai berikut: 
Gambar 2

Hasil Uji Outer Model

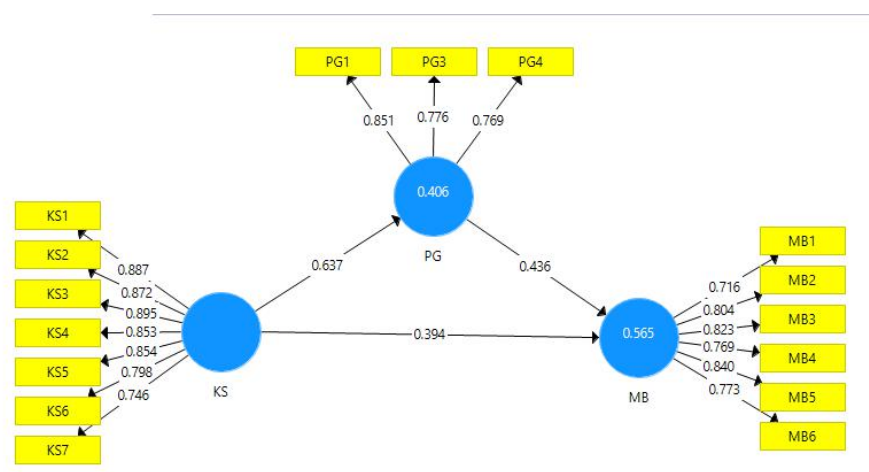

Tabel 1

Hasil Uji Validitas Konvergen

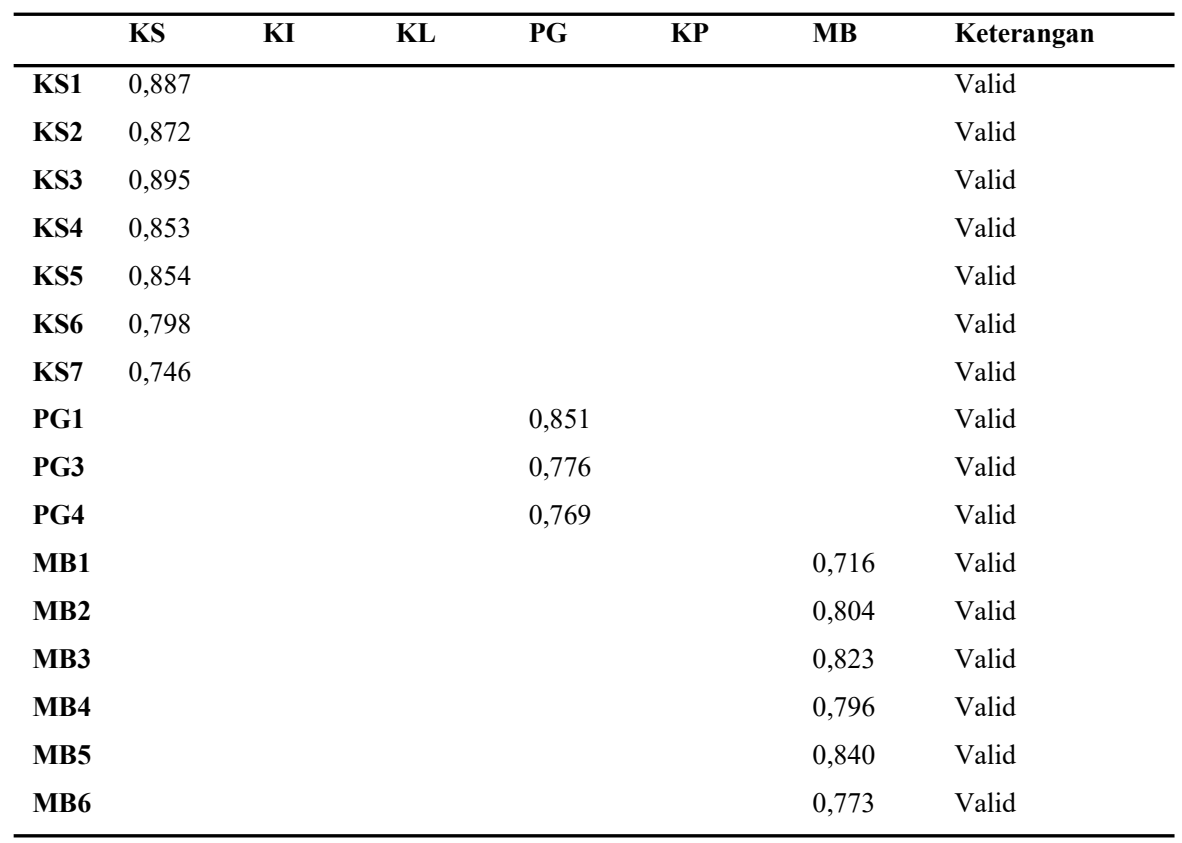

Sumber: Data primer diolah 2019

Berdasarkan tabel 4.6 menunjukkan bahwa semua item pernyataan dinyatakan valid. Hal tersebut dibuktikan dengan nilai loading factor diatas 0,50 . Selain uji validitas konvergen, dalam penelitian ini juga dilakukan uji reliabilitas menggunakan SmartPLS versi 3.0. Rincian hasil uji reliabilitas dapat dilihat pada tabel berikut ini: 
Tabel 2

Hasil Uji Reliabilitas

\begin{tabular}{lccc}
\hline & Composite Reliability & Cronbach's Alpha & Keterangan \\
\hline KS & 0,946 & 0,933 & Reliabel \\
PG & 0,842 & 0,732 & Reliabel \\
MB & 0,908 & 0,878 & Reliabel \\
\hline
\end{tabular}

Sumber: Data primer diolah 2019

Berdasarkan tabel 2 dapat disimpulkan bahwa semua variabel dinyatakan reliabel karena nilai composite reliability diatas 0,70 dan nilai cronbach's alpha diatas 0,60 .

\subsection{Hasil Uji Model Struktural (Inner Model)}

Setelah model diestimasi memenuhi kriteria outer model, maka akan dilakukan pengujian model struktural (inner model). Berikut ini adalah hasil uji inner model dengan bootstrapping.

Gambar 3

Hasil Uji Inner Model

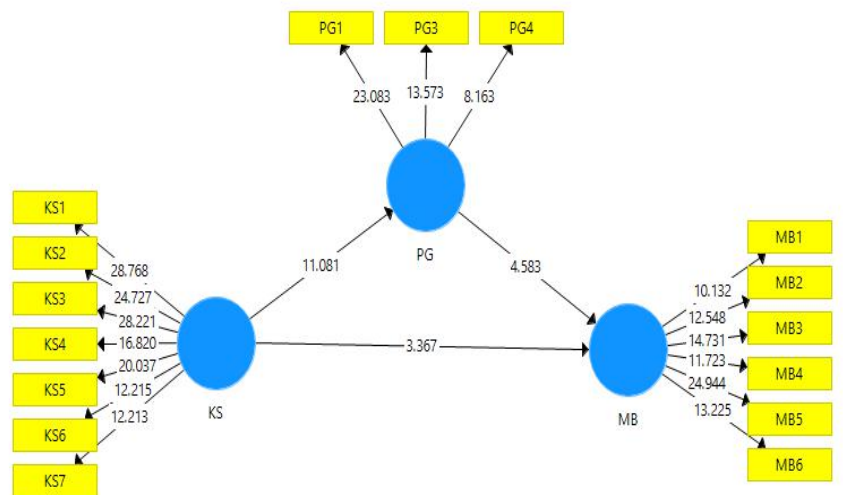

Tabel 3

Nilai $R$-Square

\begin{tabular}{cc}
\hline Variabel & $\boldsymbol{R}$-Square \\
\hline MB & 0,565 \\
PG & 0,406 \\
\hline
\end{tabular}

Sumber: Data primer diolah 2019

Berdasarkan tabel 3 dapat dilihat bahwa nilai $R$-Square untuk variabel MB sebesar 0,565 yang berarti bahwa termasuk dalam kategori sedang atau moderate. Sedangkan untuk variabel PG memiliki nilai $R$-Square sebesar 0,406 yang termasuk dalam kategori lemah. 
Tabel 4

Nilai Path Coefficients

\begin{tabular}{cccccc}
\hline & $\begin{array}{c}\text { Original } \\
\text { Sample (O) }\end{array}$ & $\begin{array}{c}\text { Sample } \\
\text { Mean } \\
(\mathrm{M})\end{array}$ & $\begin{array}{c}\text { Standard } \\
\text { Error } \\
(\text { STERR })\end{array}$ & $\begin{array}{c}\text { T Statistics } \\
(|\mathbf{O} / \mathbf{S T E R R}|)\end{array}$ & P-Values \\
\hline $\mathbf{K S}=>\mathbf{P G}$ & 0,637 & 0,646 & 0,057 & 11,081 & 0,000 \\
$\mathbf{K S}=>\mathbf{M B}$ & 0,394 & 0,378 & 0,117 & 3,367 & 0,001 \\
$\mathbf{P G = > \text { MB }}$ & 0,436 & 0,443 & 0,095 & 4,583 & 0,000 \\
\hline
\end{tabular}

Sumber: Data primer diolah 2019

Tabel 4 menunjukkan bahwa hubungan antara KS dengan PG adalah signifikan dengan nilai T-statistik sebesar 11,081 (>1,96). Nilai original sample estimate adalah positif yaitu sebesar 0,637 yang menunjukkan bahwa arah hubungan antara KS dengan PG adalah positif. Dengan demikian hipotesis H1 dalam penelitian ini yang menyatakan bahwa kualitas sistem (system quality) berpengaruh positif terhadap penggunaan (use) diterima. Hasil pengujian ini menunjukkan bahwa Mobile banking yang memiliki kualitas sistem yang baik, dapat meningkatkan tingkat penggunaan dan intesitas penggunaan layanan tersebut sebagai layanan perbankan yang user friendly dan dapat diandalkan. Tingkat penggunaan layanan mobile banking akan mencerminkan bahwa mobile banking tersebut mempunyai kualitas sistem yang bagus dan sangat membantu para penggunanya dalam melakukan transaksi perbankan mereka. Hasil penelitian ini sejalan dengan penelitian yang dilakukan oleh Purwanto et al (2017) dan Motiwalla et al (2018) yang menyatakan bahwa kualitas sistem (system quality) berpengaruh positif terhadap penggunaan (use).

Hubungan antara KS dengan MB adalah siginifikan dengan nilai T-statistik sebesar 3,367 $(>1,96)$. Nilai original sample estimate adalah positif yaitu sebesar 0,394 yang menunjukkan bahwa arah hubungan antara KS dengan MB adalah positif. Dengan demikian hipotesis H2 dalam penelitian ini yang menyatakan bahwa kualitas sistem (system quality) berpengaruh positif terhadap laba bersih (net benefits) diterima. Hasil penelitian ini menunujukkan bahwa manfaat bersih dai penggunaan mobile banking akan lebih banyak dirasakan jika ada dukungan dari kualitas system yang baik. Mobile banking yang memberi manfaat lebih banyak akan membuat para penggunanya nyaman dan tetap setia menggunakan layanan tersebut. Hasil ini juga sejalan dengan hasil penelitian yang dilakukan oleh Hafis (2016).

Hubungan antara PG dengan MB adalah signifikan dengan nilai T-statisktik sebesar 4,583 (>1,96). Nilai original sample estimate adalah positif yaitu sebesar 0,436 yang menunjukkan bahwa arah hubungan PG dengan MB adalah positif. Dengan demikian hipotesis H3 dalam penelitian ini yang menyatakan bahwa penggunaan (use) berpengaruh positif terhadap laba bersih (net benefits) diterima. Hal ini menunjukkan bahwa penggunaan yang tinggi menggambarkan manfaat yang diberikan juga tinggi. Ketika seseorang telah menggunakan mobile banking dalam waktu yang lama dan dengan intesitas yang tinggi maka manfaat yang ia rasakan juga akan semakin terasa. Hasil penelitian ini juga sejalan dengan penelitian yang dilakukan oleh Hudin \& Riana (2016).

Hubungan antara KS dengan MB melalui PG sebagai variable intervening adalah signifikan dengan nilai pengaruh langsung antara kualitas sistem terhadap laba bersih lebih besar daripada nilai pengaruh tidak langsung melalui penggunaan. Dengan demikian dapat dibuktikan bahwa penggunaan bukan merupakan variable intervening bagi hubungan kualitas sistem terhadap laba bersih. Hal ini dibuktikan melalui perhitungan nilai original estimate pada table berikut ini: 
Table 5

Ringkasan Uji Hipotesis Variabel Intervening

\begin{tabular}{|c|c|c|}
\hline KS $->>$ MB & 0,394 & $0,394>0,278$, \\
\cline { 1 - 2 } KS $>$ PG $->$ MB & $0,637 \times 0,436=0,278$ & Ditolak \\
\hline
\end{tabular}

Berdasarkan perhitungan diatas, dapat disimpulkan bahwa hipotesis H4 ditolak. Hasil penelitian ini menunjukkan bahwa kualitas sistem yang baik akan langsung mempengaruhi manfaat yang dirasakan tanpa harus memerlukan banyak waktu untuk menggunakan layanan mobile banking. Pada umumnya, banyak orang yang hanya menggunakan dalam waktu singkat dan langsung menyimpulkan bahwa layanan tersebut dapat memberikan manfaat yang lebih banyak atau tidak. Hasil penelitian ini sejalan dengan hasil penelitian yang dilakukan oleh Panjaitan, Hasibuan, Ula, \& Sembiring (2019).

Nilai tertinggi yang mempengaruhi laba bersih (MB) adalah penggunaan (PG) yaitu sebesar 0,436. Hal ini menunjukkan bahwa laba bersih (MB) lebih banyak dipengaruhi oleh penggunaan $(P G)$ daripada kualitas sistem (KS).

\section{KESIMPULAN}

Penelitian ini dilakukan terhadap 100 responden yaitu nasabah pengguna BRI Mobile baik pengguna lama maupun pengguna baru yang ada di Yogyakarta. Berdasarkan hasil penelitian ini dapat disimpulkan bahwa kualitas sistem (system quality) mobile banking berpengaruh positif terhadap penggunaan (use) mobile banking. Kualitas sistem (system quality) berpengaruh positif terhadap laba bersih (net benefits) penggunaan mobile banking. Penggunaan (use) berpengaruh positif terhadap laba bersih (net benefits) penggunaan mobile banking. Penggunaan (use) bukan merupakan variable intervening pada hubungan kualitas sistem (system quality) terhadap laba bersih (net benefits).

Kelemahan pada penelitian ini adalah penelitian ini hanya menggunakan satu sumber data yaitu menggunakan kuesioner, sehingga data yang diperoleh hanya menggambarkan pendapat dari responden. Penelitian ini juga hanya berfokus pada pengguna BRI Mobile saja bukan pengguna mobile banking secara keseluruhan. Untuk penelitian selanjutnya diharapkan untuk dapat memperluas pengambilan sampel dan menambahkan variabel tentang pengetahuan teknologi dan keamanan transaksi perbankan. 


\section{DAFTAR PUSTAKA}

DeLone, W.H and McLean, E. R. (1992). Information Systems Success: The Quest for Dependent Variable. Information System Research, 3(1). https://doi.org/10.1287/isre.3.1.60

Hafis, N. W. (2016). Analisis Kesuksesan Sistem Informasi Manajemen Menggunakan Pendekatan Updated D\&M IS Succsess Model di Rumah Sakit Umum Kaliwates Jember.

Hudin, J. M., \& Riana, D. (2016). Kajian Keberhasilan Penggunaan Sistem Informasi Accurate Dengan Menggunakan Model Kesuksesan Sistem Informasi Delon Dan Mclean. Jurnal Sistem Informasi (Journal of Information Systems), 12(1), 1-8. https://doi.org/http://dx.doi.org/10.21609/jsi.v13i1.500

Info, D. (2018). Mengatasi Aplikasi BRI Mobile Tidak Bisa Login. Retrieved from https://www.detikinfo.com/2018/09/mengatasi-aplikasi-bri-mobilebanking.html

Jogiyanto, H. (2007). Model Kesuksesan Sistem Teknologi Informasi. Yogyakarta (Vol. 1st ed).

Motiwalla, L., Albashrawi, M., \& Kartal, H. (2018). Understanding Mobile Banking Success Through User Segmentation. Proceedings of the 51 st Hawaii International Conference on System Sciences, 882-891. https://doi.org/10.24251/hicss.2018.110

Mubarok, M. T. (2015). laba bersih Sistem Informasi Akademik Di Fakultas Ilmu Adminitrasi Universitas Brawijaya( Studi Kasus Pada Mahasiswa Fakultas Ilmu Administrasi Universitas Brawijaya ). Jurnal Administrasi Bisnis, 3(1), 1-10.

Muharor, L. afghan, Busaini, \& Fitriah, N. (2015). Determinan Kesuksesan Aplikasi Sia Komdanas Pada Satuan Kerja Di Koordinator Wilayah Pengadilan Tinggi Mataram. Jurnal InFestasi, 11(1), 15-32.

Panjaitan, E. S., Hasibuan, S. F., Ula, N. M., \& Sembiring, S. (2019). Analisis Faktor-Faktor yang Mempengaruhi Manfaat Bersih yang di Mediasi oleh Kepuasan Pengguna Sistem Informasi Administrasi Kependudukan, 394-399.

Rudini, A. (2015). Pengaruh Kualitas Sistem, Kualitas Informasi, Kualitas Pelayanan SIA terhadap Kepuasan Mahasiswa (Studi Pada Mahasiswa STIE Sampit TA. 2014-2015). Jurnal Terapan Manajemen Dan Bisnis, 1(1), 39-49.

S.K, Purwanto \& Pawirosumarto, S. (2017). E-Learning Di Program Pascasarjana Universitas Mercu Buana, XXI(02), $282-305$.

TOP Brand. (2018). No Title. Retrieved from https://www.topbrand-award.com/top-brand-index/?tbi_year=2018 